\title{
Exploration of Key Technologies in a Personalized English Learning System
}

\author{
https://doi.org/10.3991/ijet.v13i07.8789 \\ Lei Ding \\ Jilin Communications Polytechnic, Jilin, China \\ dlei182edu@163.com
}

\begin{abstract}
The existing e-learning system simply presents a large number of learning resources to learners, without considering the needs of students' personalized learning, resulting in the problem of resource selection. In view of the above problems and the shortcomings of primary school English learning system, the personalized English learning system based on the e-book mode was designed and implemented. Through the design of ubiquitous resource aggregation model, course learning, resource learning, collaborative learning, unit testing, question answering system and other functions were integrated tightly together, to provide a fully personalized teaching environment for learners and teachers. The results of the system test were analyzed, and the improvement direction of the theoretical research and practical development was proposed.
\end{abstract}

Keywords-e-book; personalized learning; English resources

\section{Introduction}

Under the guidance of the new round of curriculum reform, the traditional primary school English teaching method has been unable to meet the growing needs of pupils in English learning. The Education Department of China has constantly pointed out that it is necessary to vigorously promote the information technology reform of primary school English teaching, and advocate the transformation of the teaching mode from the traditional teachers teaching and the students listening to the information, the network and the teaching software as the carrier comprehensive teaching mode. Generally speaking, English learning software can provide users with various ways of learning combined with listening, speaking, reading and writing, so that users can learn from many aspects. There are a variety of electronic English learning platforms at home and abroad. The information learning platform fully played the advantages of the human-computer interaction of the new technology, inspired the students' enthusiasm to learn, and enhanced the teaching effect while active classroom atmosphere. In addition, these teaching platforms have better interactive, timeliness and more effect sharing features, which will help to bring the dominant position of learners into full play. At present, the goal of teaching is to transform "exam oriented education" promoted by learning as a baton into "quality education" to promote the all-round devel- 
opment of students. It is an inevitable trend to promote and improve the construction of information and digitalization of English teaching in primary school.

However, in the actual learning process, the existing software lacks the dynamic adaptive ability based on the user's individualization, and does not systematically reorganize and sort the corresponding data for the level of a user's English. When users use English learning software, such as Youdao Dictionary and iCIBA, their basic operations are looking up words, looking at examples, and listening to examples. By analyzing the results of the query, it is found that, in terms of words with different difficulties, the results of the returned examples are not distinguishable and do not take into account the difficulty of the word itself and the examples that match the difficulty. The most important thing is that the query examples that are returned to different users are the same, which is not suitable for the English learners of the second language, because the user level is different and the same results are returned without distinction. It will inevitably lead to the time that users search for the learning English materials suitable for them prolonged, thus reducing user interest in learning and cannot achieve good learning results. In view of the above problems and the shortcomings of the current primary school English learning system, this paper investigates the learning needs of primary school English learners and constructs a personalized primary school English learning system. By using the characteristic information of the learners, we individualize the learning resources, construct the model of personalized learning resource aggregation and put forward the application of new intelligent recommendation technology to the learning system of primary school English so that the learners can quickly get the personalized learning resources suitable for their learning level and learning preference.

\section{State of the art}

The research and development of personalized English learning system involves many subjects, such as computer science, pedagogy, psychology, cognitive science, behavior science and so on. The ultimate aim of the research and development is the main responsibility to realize human education by computer system and promote the development of human personality. At present, computer English learning systems emerge in an endless stream at home and abroad, which meets the needs of more and more primary and secondary school students' English learning. In terms of English resources construction and electronic teaching platform, foreign related research and experiment started earlier, and its development is more rapid. Shinichi and other researchers, in 2010, proposed the design and dynamic theory of a personalized learning community (PLC), and took example to illustrate, but not limited to the general classroom environment [1]. Truccolo and other researchers proposed an online learning system for early childhood development, which provided a nationwide and secure web site where students, parents and teachers can access through the Internet [2]. The digital textbook will soon become a necessary item in every classroom of the school, and the students can get more meaningful information and learning resources in their daily learning. The foreign related institutions developed several digital resource 
learning platforms of different topics, and accumulated a lot of experience in the design of teaching function and the development of the resource learning system. Compared with foreign countries, China started relatively late in this field, but already has relatively mature market products. Researchers like Wang and others developed a "personalized courseware generation system" in 2009 [3]. The main functions include the dynamic adaptation mechanism and dynamic navigation mechanism of the learning content. This system meets the individual needs of different groups of people, integrates new technologies for intelligent teaching, and provides a powerful basis for personalized teaching. In 2010, researchers Yang and others also made a related research on personalized learning, put forward a personalized learning model, and also analyzed the functions of each module [4]. The diagnosis of personalized learning, the dynamic organization of learning content and the selection of suitable learning strategies are three main links. According to the classification and analysis of different types of students, personalized teaching content and personalized navigation of teaching content is presented. In 2015, researchers Zhao and others put forward a new personalized distance learning model. The key module of the model is personalized processing engine [5]. It is realized through three links: the collection of user information, the personalized analysis center and the information scheduling. Li and other researchers, in 2017, studied English learning based on e-book package. Its design concept is teachers as the dominant, students as the main body, following the teaching concept of new era [6]. It integrated teaching evaluation, data mining and other technologies, which have a definite innovation in terms of technique and form the half open style, and has a teacher's participation in decision support system. The domestic research on personalized learning is still in the exploratory stage. Most of the research focuses on the relevant theory of "personalized education", while the research on personalized learning is not much, and there are not many examples of specific application in practice. With the support of technical background and social objective conditions, in order to improve the efficiency of English learning and provide more effective learning system and learning strategy for students, it is urgent to reform the existing model of teaching and learning by vigorously developing personalized learning based on mobile terminal.

\section{$3 \quad$ Methodology}

\subsection{System analysis and design}

According to the characteristics of primary school English teaching, in view of the lack of individualized design, sharing design and not unified management function in the existing English teaching system, this paper puts forward the design of a personalized English learning system based on e-book model. It is based on the idea of the integration of e-book interaction design and personalized learning and provides an optimal environment for English learning.

The first is the requirement analysis of the system. In view of the problems of the existing English teaching system, the functions of the individualized primary English learning system based on e-book model are proposed. Firstly, the individual infor- 
mation of the learners is collected, and the electronic archives are set up for each learner as a basis for the system to serve the learners. In the process of line learning and operation, the students' individualized information is constantly acquired and updated. Secondly, in accordance with the judgment of learners' learning results and knowledge demand, the system can extract the personalized learning resources from the resources database of the system based on certain resource extraction algorithm. Thirdly, the system can combine the various types of resources required by the learners in an adaptive hypermedia form and appear dynamically in the form of e-books. Fourthly, the system can allow students to share their learning experience and learning methods, and share their e-books and learning content among their friends. Students can comment on each other's homework and participate in reviews and evaluations of resources and learning activities. Fifthly, the system can monitor data based on learners' learning status, and provide real-time learning effectiveness evaluation. The system provides a learning test module and after the completion of the test process, the learner can record the test process and provide an effective assessment of the learning situation. Eventually, the system provides the authority of the teachers and administrators for the operation of the existing repositories. In the process of resource storage, we should set up a perfect navigation mechanism to guide teachers and administrators to annotate and submit resources.

The second is the design of key functions. The decades of research at home and abroad have proved a conclusion that the students' feeling of reading in the electronic network teaching system and the feeling of paper materials are very different from the digital media resources, which is not easy to read in depth. According to this research conclusion, the system pays great attention to the presentation of electronic textbooks, personalized dynamic resource push, resource dynamic sharing, system management and peripheral auxiliary function design, which is regarded as the key function and the specific design requirements are listed. First of all, the e-book learning resources display module is designed. Based on the long-term development consideration, this system requires the e-book interface not only to adapt to the mode-based system, but also to adapt to the electronic book display of the mobile terminal. Secondly, the personalized push module of resources is designed. On the basis of the syllabus of primary school English, the system is required to provide a limited number of personalized and extended learning resources for different students' needs of different knowledge points according to their own learning level and interest preference. At the same time, the system can recombine the personalized resources that students like to be a new e-book, so as to facilitate the classification of knowledge and improve the user experience of the learners. Thirdly, the resource sharing function is designed. Sharing is one of the key points of the design for this system. The system should provide the function and environment for learning resources sharing among the students in a certain range. Fourthly, the teacher management module is designed. In order to monitor the learning situation of students and facilitate the management of learning resources, teachers can get more convenient operation in the process of lectures. The system focuses on the functions of teachers' learning and supervision and learning resources uploading. The supervision of students' learning situation requires that the login users have teachers' authority, and teachers can view the English learning situa- 
tion of the students in the class and give teacher comments to individual students. Fifthly, the peripheral auxiliary functional modules are designed. In order to achieve humanized service, the system not only needs to meet the basic requirements of resources display and upload as well as e-book learning, and at the same time, it also requires to have good peripheral auxiliary functions.

Again, it is the non-functional requirement. It is mainly divided into interface requirement, reliability requirement, open requirement and extensible requirement.

\subsection{System design idea}

The design idea of this system is to build e-textbooks based on learning resources as the core. According to the analysis of the previous functional requirements, first of all, we need to categorize and define the various functional modules of the system clearly, frame the relationships of each module, design the relevant data that the learners need in e-book learning, online test, resource review, activity participation and so on, and determine the personalized push of resources and other industries logic algorithm, so as to provide learners with complete and accurate technical support. The architecture of the system is the three-layer structure, which is convenient for data storage, business processing and system stability in the system. According to the actual needs of primary school English teaching, the system divides the users into four different categories of objects, and they are students, teachers, administrators and super administrators. The main application object of the system is the students and teachers, and the corresponding authority is set up. The students are in the "main" position in the learning process, and the teachers play the role of "leading". The system is mainly designed and developed for the application of students and teachers.

\subsection{System logic framework design}

The system has many functions and modules, and it has a certain requirement for the data processing and storage of the system. Therefore, this system will adopt the three-layer architecture based on mode, which are the data layer, the service layer and the presentation layer, as shown in Figure 1.

The main functions that the system layers complete include data layer, service layer and presentation layer. The data layer mainly realizes data storage and management, and it is implemented by supporting back-end database. By configuring the related data layer services in the business layer and doing business processing, the data processing results are then sent to other business layers or servers for further collection, processing and distribution. The role of service layer is to accept user requests sent from the presentation layer, and process logical data on the data layer. Through the interface provided by the data storage layer, the data layer is visited, and the service rules of the system are realized. The service layer can extract the required data from a variety of data sources and carry out the fusion processing. The presentation layer is the interface between system and user, which is responsible for collecting and tracking user's instruction behavior, and giving feedback information results to users. 

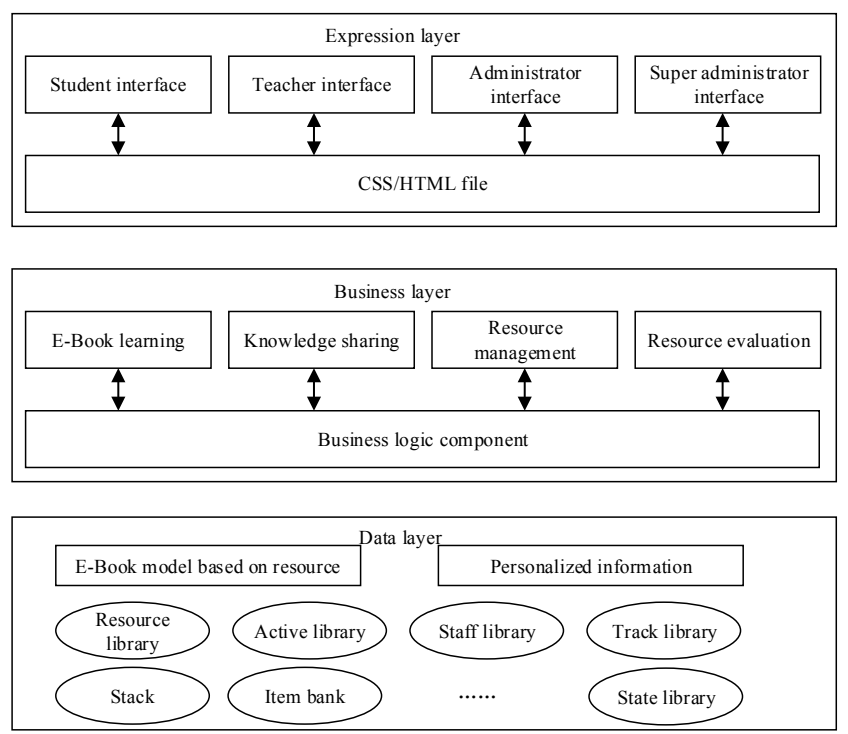

Fig.1. System structure

\subsection{Role setting}

According to the design idea of the system and the actual needs of the primary school English teaching, this system, on the basis of the role-based authority management, provide four roles of the super administrator, the administrator, the teacher and the student for users. The specific rights and functions are designed as shown in Table 1.

Table.1 System role table

\begin{tabular}{|l|l|l|}
\hline \multicolumn{1}{|c|}{ Role name } & \multicolumn{1}{|c|}{ Authorities } & \multicolumn{1}{c|}{ Function design } \\
\hline $\begin{array}{l}\text { Super administra- } \\
\text { tor }\end{array}$ & Authority management & $\begin{array}{l}\text { Super administrators can perform authority manage- } \\
\text { ment and provide functions to modify corresponding } \\
\text { user roles. }\end{array}$ \\
\hline Administrator & $\begin{array}{l}\text { User management and resource } \\
\text { management }\end{array}$ & $\begin{array}{l}\text { The administrator is responsible for the management } \\
\text { of the personnel. }\end{array}$ \\
\hline Teacher & $\begin{array}{l}\text { Teaching management, re- } \\
\text { soupervision management and student }\end{array}$ & $\begin{array}{l}\text { As the builder of the system and the guide of the } \\
\text { students, the teachers have the function of checking } \\
\text { the students' learning situation, interacting with the } \\
\text { students, and uploading the high quality English } \\
\text { learning resources so that they can manage the stu- } \\
\text { dents they teach. }\end{array}$ \\
\hline Student & $\begin{array}{l}\text { Use the system front desk } \\
\text { function and participate in } \\
\text { learning }\end{array}$ & $\begin{array}{l}\text { As the main body of learning system, students have } \\
\text { relevant rights to learn textbooks and personalized e- } \\
\text { book resources. }\end{array}$ \\
\hline
\end{tabular}




\subsection{System functional framework}

According to the functional requirement analysis of the system, a functional framework diagram of the system is designed and built. The system is divided into student terminal and management terminal. It integrates the functions of the e-book learning, resource synthesis, knowledge sharing, monitoring and analysis of the students' learning situation, management of authority and management of personnel. It provides a one-stop management of the individualized learning and management of English resources while improving the efficiency for teachers' teaching and students' learning. The system will establish the students' personal electronic learning files, accurately judge the students' current learning level, and automatically give each student the most appropriate individualized development of learning resources and appropriate learning according to the students' pre - school, post - school test results and their learning trajectory. At the same time, we can feedback students' learning to teachers. A practical English learning system considering a variety of factors, such as students' individual differences and teachers' management simplicity, has been realized. In addition, the system also has modules such as unit testing, answering questions, communication and so on, forming a complete personalized learning environment.

\section{$4 \quad$ Results and discussion}

\subsection{System technical framework}

In order to meet the requirements of a large number of complex businesses processing, the system adopts the combination design based on the Struts+Hibernate+Spring classic framework and the JQuery front page display technology. The system adopts WVC three-layer architecture (application layer, business logic layer and data layer). The Web application layer based on Struts provides human-machine interaction interface. All users of the system can login to the system through this layer and browse the specific functions of the whole system. The business logic layer and Hibernate-based persistence layer based on JavaBean (Business Object) provide background logic and data processing functions. The system manages dependencies among components through Spring container, and decouples the coupling among components from the code. The core of the primary school English resource learning system is the server side application, the front desk interface is designed with DHTML and JQuery, the background is based on the JvavEE platform, and the popular Struts, Hibernate, Spring framework is used to build, as shown in Figure 2 and Figure 3.

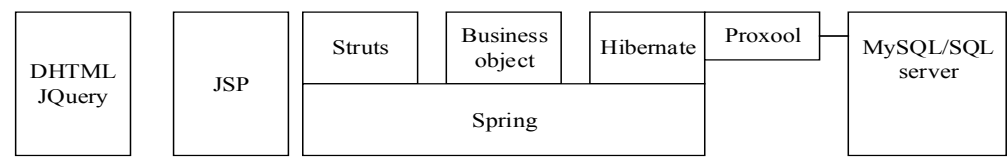

Fig.2. Core framework 


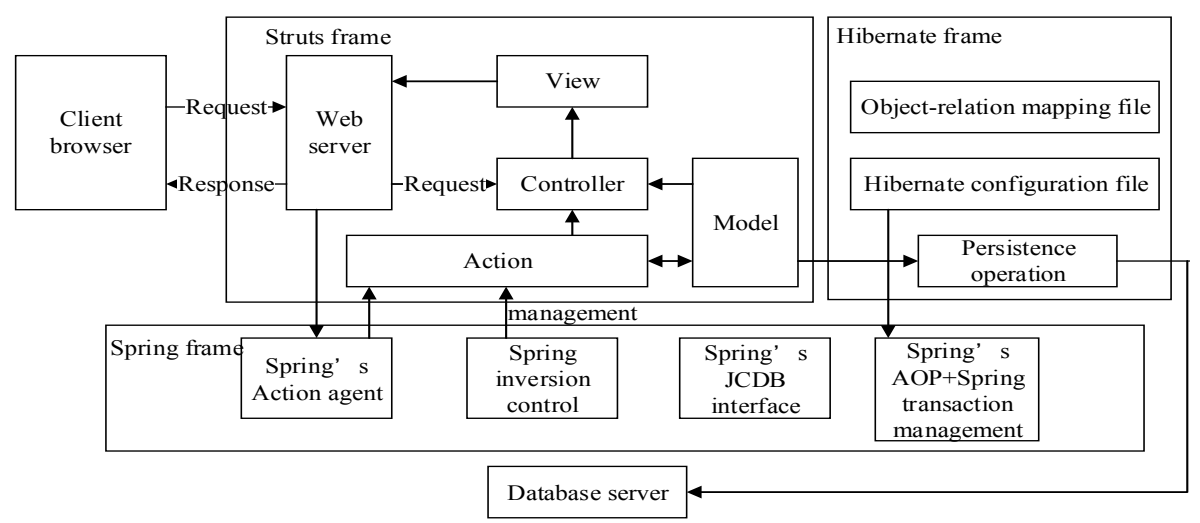

Fig.3. System overall framework

\subsection{Development environment and key technologies}

Server terminal:

- Operating system: Windows Server 2008/Ubuntu 10.

- WEB server: Tomcat7 Apache; database: MySQL5.1.

Client:

- Operating system: Windows 98/2000/XP/vista/7.

- Browser: Google browser, IE browser, Firefox browser and Apple Corp's Safari browser.

Development tools:

- WEB programing language: Java, SQL and JavaScript.

- Development environment: MyEclipse 10, AdobeDreamweaverCS5 and AdobePhotoshopCS5; development tools package: JDKVersion 1.6 and more advanced version.

JAVA-EE uses the classic Struts2+Hibernate+Spring as the framework, uses the Proxool database connection pool technology and applies the JQuery rich function library, and the system finally uses Filepage as the prototype of the e-book presentation technology. By integrating the Struts2+Hibernate+Spring framework to design the system, it can greatly improve the scalability, stability and security of the system. By using the technology of Proxool connection pool, the system has good compression ability, and the system has a good multi-browser compatibility with the latest JQuery framework technology and excellent man-machine interactive effect. 


\subsection{Implementation of the persistent layer}

The system uses Hibernate to build persistence layer framework, so as to avoid the problem of low development efficiency brought by applying traditional JBDC operation. Using Hibernate to provide support for O/RMapping, programs can operate relational databases in an object-oriented way, so that the development process of the whole software is carried out in the object-oriented side, that is, to orientate to object analysis, design and programming. In the way of designing database, the system adopts normal development mode, first of all designs data tables, and then designs objects in accordance with the data tables.

\subsection{Realization of data layer}

In the Hibernate persistence layer, the system uses general DAO components to encapsulate database operations again, which is also a commonly used DAO mode in JavaEE applications. When using the DAO mode, it embodies the facade pattern formed by the business logic component encapsulation of the DAO, and the function of separating the business logic components and DAO: the business logic component is responsible for the change of the business logic, and the DAO component is responsible for the change of the persistence technology, which is also the application of the bridging mode. After introducing the DAO model, the general DAO component contains the access logic of the database, and the DAO component can perform the basic CRUD operations on a database table.

\subsection{Achievement of business layer}

In the system, each business layer encapsulates DAO layer components. The implementation classes of all business logic interfaces in the service package of the system inherit the components corresponding to the DAO layer through the Spring dependency, and have a large number of business layer interfaces and implementation classes in the design. The business function is divided into two modules: the management - side module and the student - side module, whose main business logic is implemented through twelve business logic components, as shown in Table 2, and these twelve business logic components are used to encapsulate DAO components. The business logic layer is the core value part of the system architecture, and the business layer diagram is shown in Figure 4. The transaction management of the system is responsible for managing the business logic methods in the business logic components. The system can conveniently configure transaction management for the business logic components. When the system meets an abnormal or unexpected problem in the process of implementing the business logic, the system will automatically roll back the order of the transaction, thus greatly improving the robustness and stability of the system, and ensuring the integrity of the database data. This system manages the dependencies among the components through the Spring container, and extracts the coupling between the components from the code and manages it in the configuration file. 
Paper-Exploration of Key Technologies in a Personalized English Learning System

Table.2 Business logic function table

\begin{tabular}{|l|l|}
\hline \multicolumn{1}{|c|}{ The class name } & \multicolumn{1}{c|}{ Functions } \\
\hline IActivityPraiseService & $\begin{array}{l}\text { It provides teachers and students with relevant business logic functions of } \\
\text { activity evaluation. }\end{array}$ \\
\hline IActivityService & $\begin{array}{l}\text { It provides related business logic function realization of activity manage- } \\
\text { ment. }\end{array}$ \\
\hline IActivityTalkMapService & $\begin{array}{l}\text { It provides related business logic function achievement of activity reviews } \\
\text { and reply management. }\end{array}$ \\
\hline IActivityTalkService & $\begin{array}{l}\text { It provides relevant logic function implementation of the activity review } \\
\text { dialogue. }\end{array}$ \\
\hline IActivityWorkPraiseService & It provides related business logic function realization of activity evaluation. \\
\hline IBookService & $\begin{array}{l}\text { It provides the related business logic function achievement of e-book } \\
\text { management. }\end{array}$ \\
\hline ICrewOnlineService & $\begin{array}{l}\text { It provides the logic realization of staff online time and learning state } \\
\text { monitoring. }\end{array}$ \\
\hline ICrewService & It provides related business logic function realization of user management. \\
\hline IDescribleService & $\begin{array}{l}\text { It provides the realization of related business logic functions of knowledge } \\
\text { point labeling management. }\end{array}$ \\
\hline IExamService & $\begin{array}{l}\text { It provides the implementation of related business logic management of test } \\
\text { system performance statistics management. }\end{array}$ \\
\hline ILearnPartnerService & $\begin{array}{l}\text { It provides related business logic function achievement of learning partner } \\
\text { management. }\end{array}$ \\
\hline ILoginService & $\begin{array}{l}\text { It provides related business logic functions of user logging and account } \\
\text { management. }\end{array}$ \\
\hline
\end{tabular}

Presentation tier

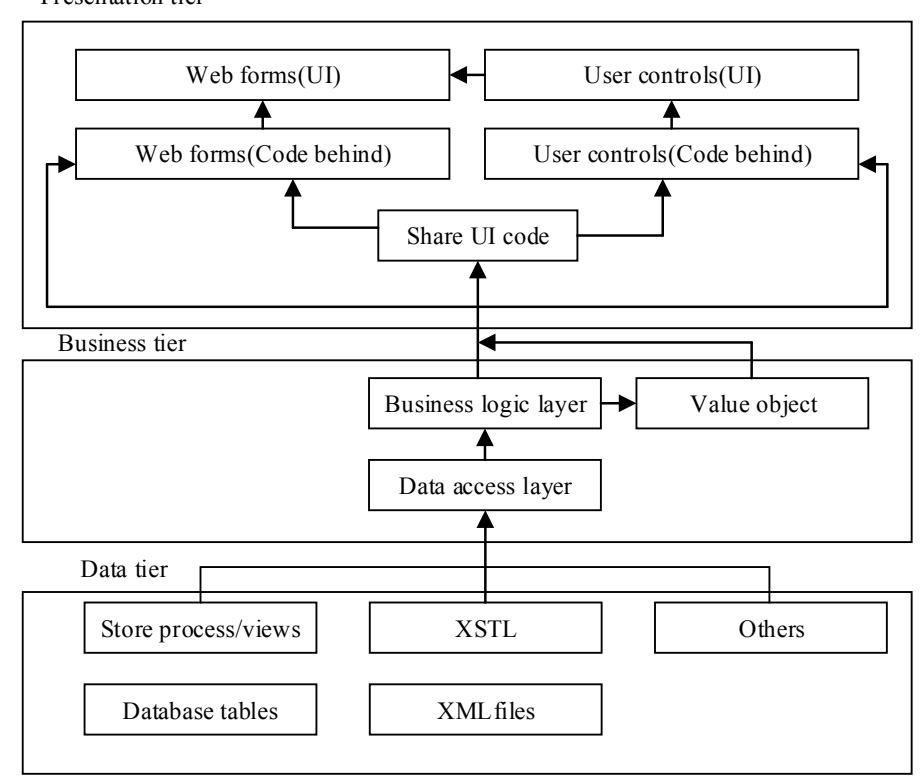

Fig.4. Business layer diagram 


\subsection{Realization of implementation layer}

In order to manage all user requests by using Struts2, the system is configured in web.xml file to cut all user requests. When the page sends requests, the request will be received by the controller. Then, the controller is responsible for calling the business logic component to deal with the requests. In order to better achieve decoupling, the Action of Struts2 in this system is only a link between user requests and business logic methods: Action needs to call a business logic component to handle user requests, and all of the business logic components of the system are managed by Spring. For this reason, the corresponding settings are made in web.xml to initialize the Spring container. When the controller receives the user request, the controller does not handle the user's request, only parse the user's request parameters and then call the business logic method to handle the user's request; when the request processing is completed, the controller is responsible for presenting the processing results to the user through the JSP page. The login page of this system is Loginebook.jsp, and when the user submits a login request, the user name and password entered by the user will be submitted to the LoginAction and invoke its execute method. This method will use the Spring container to inject the corresponding business component to identify the user's identity. Finally, Action will decide which view resources to show according to the request parameters. Besides the online answer function, the student assessment module also has the humanized online timing design. The test result module provides students with detailed test information. The pages will show students' achievements in tests, the ranking of students tested in the class, and the average test scores of students in this class. The teacher test module mainly provides the management function of examination questions library, that is, the management and operation of adding, deleting, modifying and checking specific test items.

\section{Conclusion}

English has become a universal communication language, and as the first choice of second foreign languages in China, it occupies an important position in daily teaching. English learning is a three-dimensional process, including recitation of words, grammar learning, listening practice and many other aspects, and better learning effect should be the integration of them, not independent of each other. And the process of learning English is also an extremely individualized process. The different level of English learners may be faced with different learning tasks, and the choice of resources is also different. The primary English resource learning system based on individualized e-book provides a one-stop teaching management scheme for primary school English digital teaching, such as personalized resource pushing, learning method sharing and learning statistics. It also provides a preliminary practice for exploring new English learning resources that can adapt to the future. In addition, the system reserves a rich interface for extended applications, including personalized resource pushing and resource sharing, and even the extension of network learning resource crawler, which provides a broad space for user's self-customization. 


\section{$6 \quad$ References}

[1] Shinichi, K., Nobuo, Y., Fuji, N., Tomohiko, A., Yoshio, K., \& Noriko, O., et al. (2016). The tohoku medical megabank project: design and mission:. Journal of Epidemiology, 26(9): 493-511. https://doi.org/10.2188/jea.JE20150268

[2] Truccolo, I., Mis, C. C., Cervo, S., Maso, L. D., Bongiovanni, M., \& Bearz, A., et al. (2016). Patient-centered cancer care programs in italy: benchmarking global patient education initiatives. Journal of Cancer Education, 31(2): 405-412. https://doi.org/10.1007/s1318 7-015-0805-4

[3] Wang, L. F., Liu, P. Y., Zhang, Y. C., et al (2009). Personalized study-based cai courseware system. Journal of Jilin University, 27(02): 017.

[4] Yang, J., Liu, H., \& Huang, Z. (2010). Smap: to generate the personalized learning paths for different learning style learners. Lecture Notes in Computer Science, 6249: 13-22. https://doi.org/10.1007/978-3-642-14533-9 2

[5] Zhao. J. C., Liu, S. H., \& Zhang, J. F. (2015). Personalized distance learning system based on sequence analysis algorithm. International Journal of Online Engineering, 11(7): 33. https://doi.org/10.3991/ijoe.v11i7.4764

[6] Li, S., \& Zheng, J. (2017). The effect of academic motivation on students' English learning achievement in the eSchoolbag-based learning environment. Smart Learning Environments, 4(1): 3-14. Article submitted 16 October 2017. Published as resubmitted by the authors 29 November 2017.

\section{Author}

Lei Ding is with Jilin Communications Polytechnic, Jilin, China.

Article submitted 26 April 2018. Final acceptance 07 May 2018. Finalver sion published as submitted by the author. 